Manuscript prepared for Clim. Past

with version 2015/09/17 7.94 Copernicus papers of the $\mathrm{LT}_{\mathrm{E}} \mathrm{X}$ class copernicus.cls.

Date: 11 January 2016

\title{
SUPPLEMENT OF
}

\section{A model-data assessment of the role of Southern Ocean processes in the last glacial termination}

\author{
Roland Eichinger ${ }^{1}$, Gary Shaffer ${ }^{2,3,4}$, Nelson Albarrán ${ }^{5}$, Maisa Rojas ${ }^{1}$, and \\ Fabrice Lambert ${ }^{6}$ \\ ${ }^{1}$ Department of Geophysics, University of Chile, Blanco Encalada 2002, Santiago, Chile \\ ${ }^{2}$ GAIA-Antarctica, University of Magellanes, Avenida Bulnes 01855, Punta Arenas, Chile \\ ${ }^{3}$ Center for Advanced Research in Arid Zones, Raúl Bitrán 1305, La Serena, Chile \\ ${ }^{4}$ Niels Bohr Institute, University of Copenhagen, Blegdamsvej 17, Copenhagen, Denmark \\ ${ }^{5}$ Department of Physics, University of Santiago de Chile, Avenida Ecuador 3493, Santiago, Chile \\ ${ }^{6}$ Department of Physical Geography, Catholic University of Chile, Vicuña Mackenna 4860, \\ Santiago, Chile
}

Correspondence to: Roland Eichinger (roland@ dgf.uchile.cl)

\section{Introduction}

This supplement provides additional material to the article "A model-data assessment of the role of Southern Ocean processes in the last glacial termination". This includes the description of the profile function of the ocean vertical diffusion in the high latitude model ocean applied for generating Last Glacial Maximum (LGM) conditions in the DCESS model. Furthermore, the newly developed scheme for the representation of the terrestrial biosphere in the DCESS model is presented in detail. The formulation of the vegetation zones and their impact on the atmosphere-biosphere exchange fluxes as well as an evaluation of the module is given. We also describe our treatment of dust radiative forcing and high latitude ocean iron-limitation and provide additional information about the various ${ }^{14} \mathrm{C}$ production rate time series that were applied in the model simulations.

\section{Ocean vertical diffusion profile}

In the article, we present a profile for the high latitude ocean vertical diffusion with depth, which is applied to generate an analogy to isolated Southern Ocean (SO) deep and intermediate waters (see e.g. Watson and Naveira Garabato, 2006). In this section, we present details about this profile and explain how it was established. The mathematical formulations of the profile and of the resumption to full vertical diffusion in the transient simulations are given. 


\subsection{Description of the profile}

For pre-industrial (PI) climate conditions, the ocean vertical diffusion parameter is set to $D_{P I}=$ $2.3 \cdot 10^{-3} \mathrm{~m}^{2} \mathrm{~s}^{-1}$ evenly throughout the high latitude DCESS model ocean. To generate isolated deep water and thereby LGM climate conditions, we impose the function

$D_{p}=\left[\left(0.5 \cdot \tanh \left(-d \cdot 0.3+p_{a}\right)\right)+0.5\right] \cdot k v_{\max }+k v_{\min }$,

on this parameter. This signifies a sharp reduction of the high latitude ocean vertical exchange at an ocean depth depending on $p_{a}$ (see below). Here, $d$ denotes the ocean depth (in $\mathrm{m}$ ) and the factor 0.3 was chosen as a best-guess to set the steepness of the transition.

$k v_{\max }=R_{C} \cdot p_{\min } \cdot D_{P I}$

and

$k v_{\text {min }}=R_{C} \cdot\left(1-p_{\text {min }}\right) \cdot D_{P I}$

are used to calculate the maximum and the minimum of the diffusion profiles in relation to the standard value for PI conditions $\left(D_{P I}=2.3 \cdot 10^{-3} \mathrm{~m}^{2} \mathrm{~s}^{-1}\right)$. Here, $p_{\text {min }}$ represents the relative minimum of the diffusion, which is set to 0.03 , and $R_{C}$ determines the change of diffusivity above the transition. However, the minimum of the vertical diffusion by depth is determined by the low latitude ocean value

$D_{p, \min }=2 \cdot 10^{-5} \cdot\left[1+5.5 \cdot\left(1-\exp \left(\frac{d}{40}\right)\right)\right]$

and imposed by computing $D_{p, t o t}=\max \left(D_{p}, D_{p, \min }\right)$. We used $R_{C}=1.0$ to keep the parameter at standard PI conditions in the shallow ocean for simplicity.

For our efforts to generate an LGM climate state, which constrains all the mentioned variables to proxy data records concurrently, we used the parameter $p_{a}$ to vary the transition depth and thereby the oceanic volume of isolated deep water. This yielded $p_{a}=5$ for the presented representation of LGM climate, which implies a transition at around $1800 \mathrm{~m}$ depth.

\subsection{Resumption of deep ocean mixing}

In order to simulate the resumption of deep ocean mixing during the Mystery Interval (MI), we impose a steady deepening of the transition depth of the imposed vertical diffusion profile. Starting at year $17.5 \mathrm{kaBP}$ we modify $p_{a}$ in Eq.1 1 by

$45 p_{a}=5+\frac{n}{100} \cdot 0.5$,

where $\mathrm{n}$ denotes the time step after the start of the resumption. This steadily decreases the transition depth of the vertical diffusion ocean profile over time. Effectively, it leads to the resumption of the 
high latitude ocean to PI mixing within around the $3 \mathrm{ka}$ of the MI. In other words, this simulates a steady, time-dependent upwelling of the deep ocean waters that had been isolated through the imposed vertical mixing profile. Thus, it describes an analogy to the sudden event of deep ocean mixing during the MI, that has been hypothesised in a number of studies (e.g. Burke and Robinson. 2012).

\section{The new terrestrial biosphere scheme}

Here, we provide a detailed description of the newly developed terrestrial biosphere scheme of the

DCESS model. First, a presentation of the characteristics of the chosen vegetation zones and their latitudinally variable borders is given. Then, the new calculations of the biosphere-atmosphere exchange fluxes of $\mathrm{CO}_{2}$ and $\mathrm{CH}_{4}$ for ${ }^{12} \mathrm{C}$ as well as for the rare carbon isotopes ${ }^{13} \mathrm{C}$ and ${ }^{14} \mathrm{C}$ are shown. Moreover, in this section, we provide a brief evaluation of the new module, in order to ascertain that the general purpose of this biosphere scheme, the representation of land-atmosphere carbon fluxes across the last glacial termination, is reasonable with this approach.

\subsection{Description of the vegetation zones}

Based on the modelling study by Gerber et al. (2004), we defined a latitudinal distinction of three vegetation zones, tropical forests (TF), grasslands, savanna and deserts (GSD) and extratropical forests $(\mathrm{EF})$. Tab. 1 shows the characteristic values of biomass reservoirs and net primary production (NPP) of those vegetation zones at PI climate conditions for one hemisphere (Saugier et al., 2001. Gower et al., 1999; Sterner and Elser, 2002; Zheng et al., 2003; Chapin et al., 2011). The values in Tab. 1 have been constrained such that the sum over the three vegetation zones adds up to PI values of the original biosphere model (Shaffer et al., 2008).

\begin{tabular}{|l|c|c|c|}
\hline & $\begin{array}{c}\text { Tropical } \\
\text { forest }\end{array}$ & $\begin{array}{c}\text { Boreal } \\
\text { forest }\end{array}$ & $\begin{array}{c}\text { Grassland } \\
\text { savanna } \\
\text { desert }\end{array}$ \\
\hline Leaves / GtC & 15 & 25 & 10 \\
Wood / GtC & 135 & 25 & 90 \\
Litter / GtC & 8 & 20 & 32 \\
Soil / GtC & 100 & 250 & 400 \\
NPP / Gt $\cdot a^{-1}$ & 12.5 & 10 & 7.5 \\
\hline
\end{tabular}

Table 1. Distribution of biomass reservoirs and net primary production of the different vegetation zones at PI conditions, globally averaged for one hemisphere adjusted to the DCESS model geometry (see Chapin et al. 2011, and citations therein). 
The latitudinal limits of these vegetation zones are dynamically defined. In general, the extent of certain vegetation zones depends mainly on temperatures and precipitation. However, the limitations of the DCESS model require a somewhat more general approach. We therefore determine the division of the three vegetation zones solely by the deviation of the global mean atmosphere temperature from its PI value. For this purpose, we derived two polynomial functions from a study by Gerber et al. (2004, in particular from the results in their Fig. 4). In that study, the complex LPJ vegetation model (Lund-Potsdam-Jena Dynamic Global Vegetation Model) was applied to distinguish between a number of vegetation zones based on several variables. The two latitudinal limitations of the vegetation zones are described by the two 5th order polynomials

$$
\begin{aligned}
L_{T F-G S D}= & -1.83 \cdot 10^{-5} \cdot \delta T_{\text {glob }}^{5}-0.0005809 \cdot \delta T_{\text {glob }}^{4}-0.005168 \cdot \delta T_{\text {glob }}^{3} \\
& +0.0497 \cdot \delta T_{\text {glob }}^{2}+1.092 \cdot \delta T_{\text {glob }}+11.28
\end{aligned}
$$

and

$$
\begin{aligned}
L_{G S D-E F}= & 1.152 \cdot 10^{-5} \cdot \delta T_{\text {glob }}^{5}-0.0001785 \cdot \delta T_{\text {glob }}^{5}-0.004557 \cdot \delta T_{\text {glob }}^{3} \\
& +0.04156 \cdot \delta T_{\text {glob }}^{2}+1.017 \cdot \delta T_{\text {glob }}+37.77
\end{aligned}
$$

which depend only on the deviation of the global mean atmosphere temperature $\delta T_{g l o b} . L_{T F-G S D}$ denotes the latitude of the border between the TF and the GSD zones and $L_{G S D-E F}$ the latitude between GSD and EF. These two 5th order polynomials are illustrated in Fig. 1 .

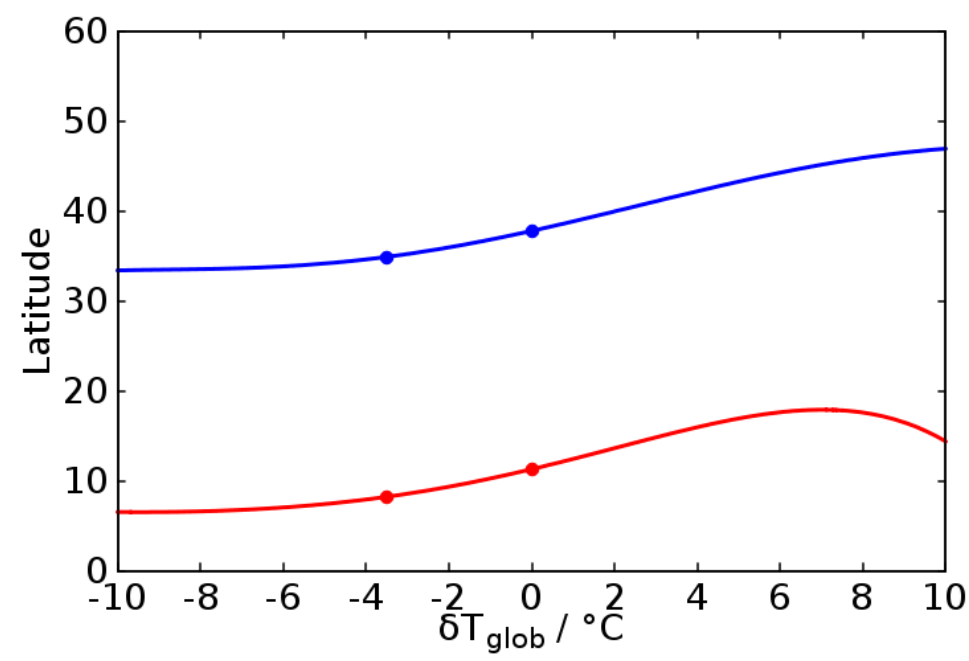

Figure 1. Polynomial functions describing the dynamic latitudes of the borders between the three vegetation zones dependent on the deviation of the global mean atmosphere temperature $\delta T_{g l o b}$. Red: Border between the TF and the GSD zone $\left(L_{T F-G S D}\right)$. Blue: Border between the GSD and the EF zone $\left(L_{G S D-E F}\right)$. The dots mark the conditions at $\mathrm{PI}\left(\delta T_{g l o b, P I}=0^{\circ} \mathrm{C} ; L_{T F-G S D, P I}=11.28^{\circ}, L_{G S D-E F, P I}=37.77^{\circ}\right)$ and LGM $\left(\delta T_{\text {glob }, L G M}=-3.5^{\circ} \mathrm{C} ; L_{T F-G S D, P I}=7.17^{\circ} ; L_{G S D-E F, P I}=33.92^{\circ}\right)$ climate state. 
The EF vegetation zone additionally is limited by either the snowline (defined as the latitude of $0^{\circ} \mathrm{C}$ global mean temperature) or the line of the terrestrial ice sheet extent, depending on which one of the two lines expands the farthest from the pole at the current time step (see next section). Based on these latitudinal limits, the total $\mathrm{CO}_{2}$ and $\mathrm{CH}_{4}$ fluxes between the terrestrial biosphere and the atmosphere are now determined by the sum of the three vegetation zones and dependent on the respectively covered vegetation areas as well as their current values of NPP and stored biomass.

\subsection{Extension of the carbon flux equations}

The equation

$N P P=N P P_{P I}\left(1+F_{C O 2} \cdot \ln \left(\frac{p C O_{2}}{p C O_{2, P I}}\right)\right)$

from Shaffer et al. (2008) for the NPP is now subdivided into the three equations

$N P P_{T F}=N P P_{T F, P I} \cdot A_{T F} \cdot\left(1+f_{C O 2} \cdot \ln \left(\frac{p C O_{2}}{p C O_{2, P I}}\right)\right)$,

$N P P_{G S D}=N P P_{G S D, P I} \cdot A_{G S D} \cdot\left(1+f_{C O 2} \cdot \ln \left(\frac{p C O_{2}}{p C O_{2, P I}}\right)\right)$

85 and

$N P P_{E F}=N P P_{E F, P I} \cdot A_{E F} \cdot\left(1+f_{C O 2} \cdot \ln \left(\frac{p C O_{2}}{p C O_{2, P I}}\right)\right)$

for the different vegetation zones, respectively. The factors $A_{T F}, A_{G S D}$ and $A_{E F}$ are calculated by $A_{T F}=\frac{\sin \left(L_{T F-G S D}\right)}{\sin \left(L_{T F-G S D, P I}\right)}$

$A_{G S D}=\frac{\sin \left(L_{G S D-E F}-L_{T F-G S D}\right)}{\sin \left(L_{G S D-E F_{P} I}-L_{T F-G S D, P I}\right)}$

and

$A_{E F}=\frac{\sin \left(L_{s}\right)-\sin \left(L_{G S D-E F}\right)}{\sin \left(L_{s, P I}\right)-\sin \left(L_{G S D-E F, P I}\right)}$

and scale the contributions of the respective NPP by the current area of the individual vegetation zone. The index $P I$ stands for reference PI conditions and $f_{C O 2}$ for the $\mathrm{CO}_{2}$ fertilisation factor.

In the original configuration, this factor was set to 0.65 , which was in good agreement with results by Friedlingstein et al. (2006). However, a revision of this value in a model intercomparison study yielded a lower value of 0.37 to be a more suitable value for the terrestrial biosphere (Zickfeld et al. 2013) and thus has also been used in the present study. Now, the four conservation equations per carbon isotope $\left({ }^{12,13,14} \mathrm{C}\right.$ ) (see Shaffer et al., 2008) have to be calculated for each vegetation 
zone separately. The losses for reservoir size of litter and soil were dependent on the mean global atmosphere temperature in Shaffer et al. (2008) for the uniform vegetation. Now, we approximate a mean atmosphere temperature for each vegetation zone separately by

$$
\begin{aligned}
T_{T F}= & \frac{\left(T_{a t m, L L}-0.5 \cdot T_{a t m, H L}\right) \cdot \sin \left(L_{T F-G S D}\right)+0.5 \cdot T_{a t m, H L} \cdot \sin \left(L_{T F-G S D}\right)^{3}}{\sin \left(L_{T F-G S D}\right)}, \\
T_{G S D}= & \frac{\left(T_{a t m, L L}-0.5 \cdot T_{a t m, H L}\right) \cdot\left(\sin \left(L_{G S D-E F}\right)-\sin \left(L_{T F-G S D}\right)\right.}{\sin \left(L_{G S D-E F}\right)-\sin \left(L_{T F-G S D}\right)} \\
& +\frac{0.5 \cdot T_{a t m, H L} \cdot\left(\sin \left(L_{G S D-E F}\right)^{3}-\sin \left(L_{T F-G S D}\right)^{3}\right)}{\sin \left(L_{G S D-E F}\right)-\sin \left(L_{T F-G S D}\right)}
\end{aligned}
$$

and

$$
\begin{aligned}
T_{E F} & =\frac{\left(T_{a t m, L L}-0.5 \cdot T_{a t m, H L}\right) \cdot\left(\sin \left(L_{\text {snow } / \text { ice }}\right)-\sin \left(L_{T F-G S D}\right)\right)}{\sin \left(L_{\text {snow } / \text { ice }}\right)-\sin \left(L_{T F-G S D}\right)} \\
& +\frac{0.5 \cdot T_{a t m, H L} \cdot\left(\sin \left(L_{\text {snow } / \text { ice }}\right)^{3}-\sin \left(L_{T F-G S D}\right)^{3}\right)}{\sin \left(L_{\text {snow } / \text { ice }}\right)-\sin \left(L_{T F-G S D}\right)},
\end{aligned}
$$

in order to achieve a more realistic dependency of this process. Here, $T_{a t m, L L}$ denotes the mean atmosphere temperature in the low latitude sector and $T_{a t m, H L}$ in the high latitude sector. $L_{\text {snow } / \text { ice }}$ stands for the minimum of the latitude of the snow and the ice sheet line. The fluxes between the terrestrial biosphere and the atmosphere are determined by

$$
\begin{aligned}
F_{C O_{2}} & =\left(-N P P_{T F}+\frac{45}{55} \Delta L_{T F} \cdot L_{T F}+\Delta S_{T F} \cdot S_{T F}\right) \\
& +\left(-N P P_{G S D}+\frac{45}{55} \Delta L_{G S D} \cdot L_{G S D}+\Delta S_{G S D} \cdot S_{G S D}\right) \\
& +\left(-N P P_{E F}+\frac{45}{55} \Delta L_{E F} \cdot L_{E F}+\Delta S_{E F} \cdot S_{E F}\right)
\end{aligned}
$$

for carbon dioxide and by

$F_{C H_{4}}=L B M P_{T F}+L B M P_{G S D}+L B M P_{E F}$

for methane. Here, $L_{i}$ and $S_{i}$ represent the biomass carbon reservoirs in litter and soil for the different vegetation zones, respectively, and $\Delta L_{i}$ and $\Delta S_{i}$ their decay rates. For the two rare carbon isotopes, additionally the corresponding fractionation factors ${ }^{13,14} \alpha$ have to be considered. The fluxes are then given by

$$
\begin{aligned}
F_{13,14} C O_{2} & =\left(-N P P_{T F} \cdot \frac{13,14 C}{12 C} \cdot{ }^{13,14} \alpha+\frac{45}{55} \Delta L_{T F} \cdot{ }^{13,14} L_{T F}+\Delta S_{T F} \cdot{ }^{13,14} S_{T F}\right) \\
& +\left(-N P P_{G S D} \cdot \frac{13,14 C}{12 C} \cdot{ }^{13,14} \alpha+\frac{45}{55} \Delta L_{G S D} \cdot{ }^{13,14} L_{G S D}+\Delta S_{G S D} \cdot{ }^{13,14} S_{G S D}\right) \\
& +\left(-N P P_{E F} \cdot \frac{13,14 C}{{ }^{12} C} \cdot{ }^{13,14} \alpha+\frac{45}{55} \Delta L_{E F} \cdot{ }^{13,14} L_{E F}+\Delta S_{E F} \cdot{ }^{13,14} S_{E F}\right)
\end{aligned}
$$

and

$$
F_{13,14} C H_{4}=L B M P_{T F} \cdot \frac{13,14 S_{T F}}{12 S_{T F}}+L B M P_{G S D} \cdot \frac{13,14 S_{G S D}}{12 S_{G S D}}+L B M P_{E F} \cdot \frac{13,14 S_{E F}}{12 S_{E F}} .
$$


Due to global temperature changes on glacial-interglacial time scales, $L_{\text {snow } / \text { ice }}$ advances and retreats on large spatial scales and thus organic carbon is buried/released below/from permafrost areas.

Therefore, additional land-atmosphere carbon flux variations due to the changes of permafrost area have to be considered. For this, we add the permafrost flux term ${ }^{12,13,14} F_{C O_{2}, P F}$ to Eqs. 18 to 21 which is calculated by

${ }^{12,13,14} F_{C O_{2}, P F}=\Delta A_{\text {snow } / \text { ice }} \cdot{ }^{12,13,14} C_{P F}$.

Since the contribution of carbon release from permafrost to methane is very small and moreover, we prescribe the methane radiative forcing in our simulations, we neglect the separation of these effects here. $\Delta A_{\text {snow/ice }}$ denotes the change in snow or ice covered area and is computed by

$\Delta A_{\text {snow } / \text { ice }}=2 \pi R \cdot\left(1-\frac{270}{360}\left(\left(1-\sin \left(L_{\text {snow } / \text { ice }, t}\right)\right)-\left(1-\sin \left(L_{\text {snow } / \text { ice }, t-1}\right)\right)\right)\right.$.

For this, the respective minimum of the snow- or the iceline $\left(L_{\text {snow } / i c e}\right)$ of the previous $(t-1)$ and the current $(t)$ time step is taken. $\mathrm{R}$ denotes the Earth radius and the factor $(270 / 360)$ takes account for the land fraction in the model geometry.

${ }^{12} C_{P F}$, the amount of carbon being stored in permafrost, was approximated to $30 \mathrm{~kg} \cdot \mathrm{m}^{-2}$ by Schuur et al. 2015). For the stable ${ }^{13} C_{P F}$ isotope, carbon is buried and released through permafrost with the same isotope ratio. We hence set the value to $0.33 \mathrm{~kg} \cdot \mathrm{m}^{-2}$, to yield a typical isotope ratio for EF soil of $\delta^{13} C=-24 \%$. For ${ }^{14} C_{P F}$, however, radioactive decay $\left(T_{1 / 2}\left({ }^{14} C\right)=5730\right.$ a) across the entire last glacial period, when large parts of the high latitudes were covered by terrestrial ice sheets, has to be considered. We therefore assume carbon to be released from permafrost radiocarbon dead $\left(\Delta^{14} C=-1000 \%\right.$ o) during the last deglaciation (see also Zech, 2012), while being buried with the current isotope ratio of soil. As is, the land area of the model simply covers $1 / 3$ of the globe across all latitudes. In our configuration for the last glacial termination, the permafrost affects latitudes between $47^{\circ}$ and around $54^{\circ}$ (see Fig. 3 in the manuscript). Across these latitudes, the land fraction averaged over both hemispheres is around 30\% (see e.g. Matney, 2012). Thus, a further adjustment for the permafrost effect due to land fraction was not considered to be necessary.

\subsection{Evaluation of the new biosphere scheme}

In order to demonstrate that the newly developed land biosphere scheme in the framework of the

DCESS model adequately represents the different vegetation zones for global climate changes and thus meets the needs for the simulation of the last glacial termination, we here present a brief evaluation of the new module. For this purpose, we show the reaction of the model vegetation zones and the different vegetation reservoirs on a reduction and an increase of the atmospheric temperatures and $\mathrm{pCO}_{2}$. Moreover, we compare the results of the cooling experiment with complex vegetation models as well as with data reconstructions.

The maximum rise in atmospheric temperatures in future climate change simulations with the DCESS model is around $5.2^{\circ} \mathrm{C}$ at year 2100 (in the A2 emission scenario, see Shaffer et al., 2009). 
For the evaluation, we carried out two warming simulations (with and without the new biosphere scheme) with a gradual increase of $\mathrm{pCO}_{2}$ to $1000 \mathrm{ppm}$ within around $300 \mathrm{a}$ and fix the global mean atmosphere temperature $\left(\mathrm{T}_{\text {glob }}\right)$ once it has risen by $5.2{ }^{\circ} \mathrm{C}$. The left panel of Fig. 2 shows the land biomass carbon (LB) for the three individual vegetation zones and their sum for the two warming simulations and the right panel shows the global sum of LB of the vegetation reservoirs above ground (leaves + wood) and below ground (litter + soil). Since the system seems to be in equilibrium after around $1 \mathrm{ka}$, we integrated these simulations over $2 \mathrm{ka}$.
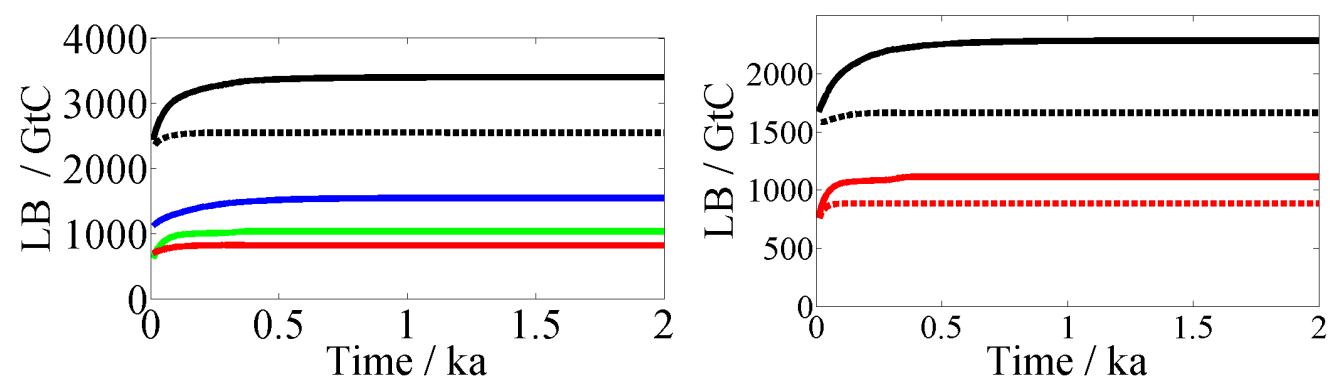

Figure 2. Warming simulation (see text) for the model version with the new (solid) and the old (dashed) vegetation scheme. Left panel: Total land biomass carbon (in black) separated into the three vegetation zones (TF: green, GSD: red, EF: blue). Right panel: Land biomass carbon separated into the vegetation reservoirs above ground (leaves + wood) in red and below ground (litter + soil) in black.

The warming experiment shows an overall increase in land biomass in both simulations, with more change in the simulation with the new biosphere scheme. The land biomass change happens slower in the simulation with the new biosphere scheme, because the land biomass changes in the EF zone mainly depends on variations in soil, which has a slow response time and is the largest biomass reservoir. The TF zone adapts much quicker to the new climate conditions, because in this vegetation type the biomass is dominated by leaves and wood.

To evaluate the vegetation scheme for LGM conditions, we carried out two cooling simulations. For these, we gradually decreased the temperature until $\mathrm{T}_{g l o b}=11.5^{\circ} \mathrm{C}$ was reached and prescribed the atmospheric $\mathrm{pCO}_{2}$ to $190 \mathrm{ppm}$. Fig. 3 shows the results of this cooling experiment, depicted as in the warming experiment above.

Here, basically the same effects as in the warming experiment can be observed. The overall change is larger in the simulation with the new biosphere scheme. The GSD vegetation zone shows the smallest change in biomass in both experiments, because the area of this vegetation zone changes only little, it rather just shifts latitudinally.

We calibrated the latitudinal dependency of the vegetation zone borders to match the LPJ model results. However, the calculation of carbon stored in the terrestrial biosphere at different climate conditions also depends on other parameters. Hence, we first evaluate the performance of the new 

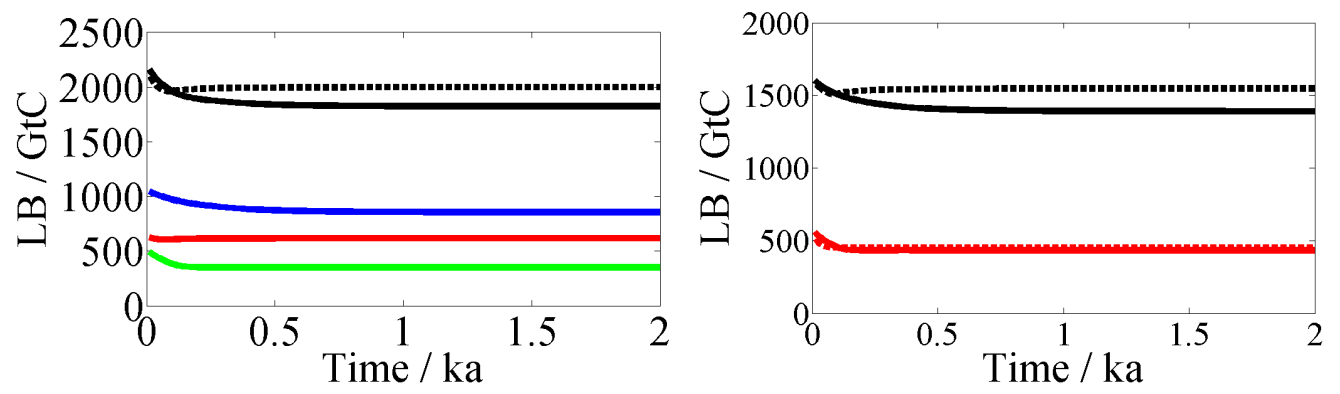

Figure 3. Same as Fig. 2 but for the cooling experiment (see text).

DCESS vegetation scheme by comparing to the results of the LPJ model study by Gerber et al. (2004). For this, Tab. 2 shows the change of biomass carbon in the cooling experiment with the new and the old DCESS model version and the LPJ model.

\begin{tabular}{|l|c|c|c|}
\hline$\Delta$ LB / \% & Total & Litter + Soil & Leaves + Wood \\
\hline Old bio & -10.0 & -4.4 & -24.8 \\
New bio & -17.8 & -14.1 & -27.8 \\
LPJ & -24.8 & -24.7 & -25.0 \\
\hline
\end{tabular}

Table 2. Percentual change of biomass carbon in the cooling experiment for total vegetation and divided into the vegetation reservoirs above and below ground. DCESS model with old and with new biosphere scheme and LPJ model study presented in Gerber et al. (2004).

This comparison demonstrates that in relation to the LPJ model, the adaptation of the land biomass to different climate conditions improved significantly from the DCESS model without the new biosphere scheme to the current version. While with the old model version, biomass carbon decreased by less than half of the LPJ model change, the new biosphere scheme produces about $70 \%$ of that change. Most of the improvement in land biomass variations through the new vegetation scheme is due to a better representation of litter and soil. The computation of leaves and wood only improved slightly from the old model version to the new one, however, it had already been in fairly well agreement with the LPJ model before. Hence, the reason for the much larger changes in overall biomass between the old and the new model version as shown in Figs. 2 and 3 is mainly due to the better representation of the slow change of the soil biomass in the EF zone. This more accurate representation of soil in the EF zone, again, is also due to the fact that now the biomass reservoirs of each vegetation zone depend on the specific temperature of this particular vegetation zone and not on the global mean temperature as in the old model version. 
Peng et al. (1998) provide an overview of various studies that estimate the difference in global

$$
\text { (GCM) simulations, marine carbon isotope data changes or vegetation mapping approaches. Alto- }
$$
gether, these studies show a large spread from 0 (Prentice and Fung, 1990) to 1350 GtC (Adams et al. 1990). The majority of the studies provide values between 300 and 700 GtC difference between the two climate states, a more recent modelling study by Prentice et al. (2011) provides values of $550-694 G t C$. Hence, through the implementation of the new vegetation scheme, the DCESS model biomass carbon change between PI and LGM does improve from 221 to 396 GtC, however, it is still rather on the low end of the uncertainty range.

Overall, it can be stated that the new biosphere scheme with the three vegetation zones constitutes a significant improvement for the representation of the terrestrial biomass, and thereby also the land-atmosphere carbon exchange rates in the DCESS model. This new implementation allows more nuanced investigations concerning the complex interactions between the terrestrial and the atmospheric carbon exchange that is required to obtain a better understanding of the processes that determine the climate change from the LGM to the Holocene.

\section{Transition function for dust concentration}

As described in the manuscript, the dustier atmosphere during LGM climate conditions (e.g. Maher et al. 2010) leads to the assumptions of an additional radiative forcing $\left(A_{\text {Dust }}\right)$ of $-1 \mathrm{Wm}^{2}$ (see Mahowald et al. 2006) and an increased iron limitation factor $\left(f_{F e-l i m}\right)$ in the high latitude ocean (Lambert et al. 2013, 2015). For the transition of these parameters between LGM and PI conditions in the transient simulations, we applied functions derived from the correlation between dust flux and global mean atmosphere temperatures in proxy data records. Fig. 4 shows proxy data records from Antarctica of the dust flux and the temperature (Jouzel et al., 2007; Lambert et al., 2012). As stated in Lambert et al. (2012), the major changes in dust flux occurred before $15 \mathrm{kaBP}$. An analysis of the correlation of the two quantities provides an exponential dependency with an exponent of -0.4 . The same climate-dust exponential relationship also holds true for a remote site from the central Pacific 210 (Winckler et al. 2008).

This relationship provides a relatively simple approach for the temperature-dependent transition functions of $A_{D u s t}$ and $f_{F e-l i m}$ from LGM to PI conditions. For this, we use the conditions $f_{F e-l i m}=0.36$ for PI $\left(T_{g l o b}=15^{\circ} C\right)$ and $f_{F e-l i m}=0.5$ (see manuscript) for LGM $\left(T_{g l o b}=\right.$ $11.5^{\circ} \mathrm{C}$ ) and $A_{D u s t}=0$ for PI and $A_{D u s t}=-1$ for LGM. With the function $a \cdot e^{-0.4 \cdot T_{g l o b}}+b$ for

215 the correlation between $T_{g l o b}$ and dust flux during this period derived from proxy data, the transition functions

$f_{F e-l i m}=\frac{0.14 \cdot e^{-0.4 \cdot T_{\text {glob }}}+0.36 \cdot e^{-4.6}-0.5 \cdot e^{-6}}{e^{-4.6}-e^{-6}}$ 


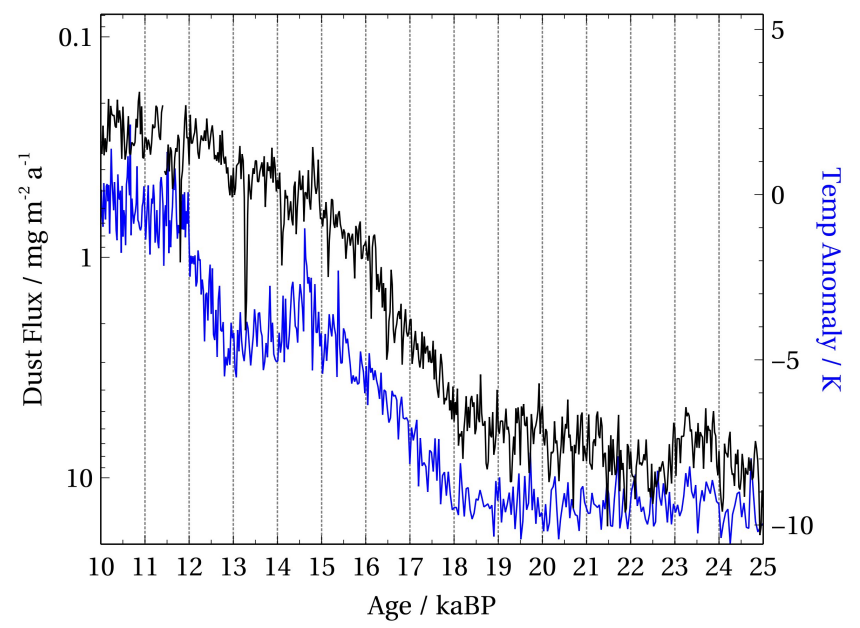

Figure 4. Dust fluxes and Antarctic temperature anomaly across the last glacial termination (Jouzel et al. 2007; Lambert et al. 2012).
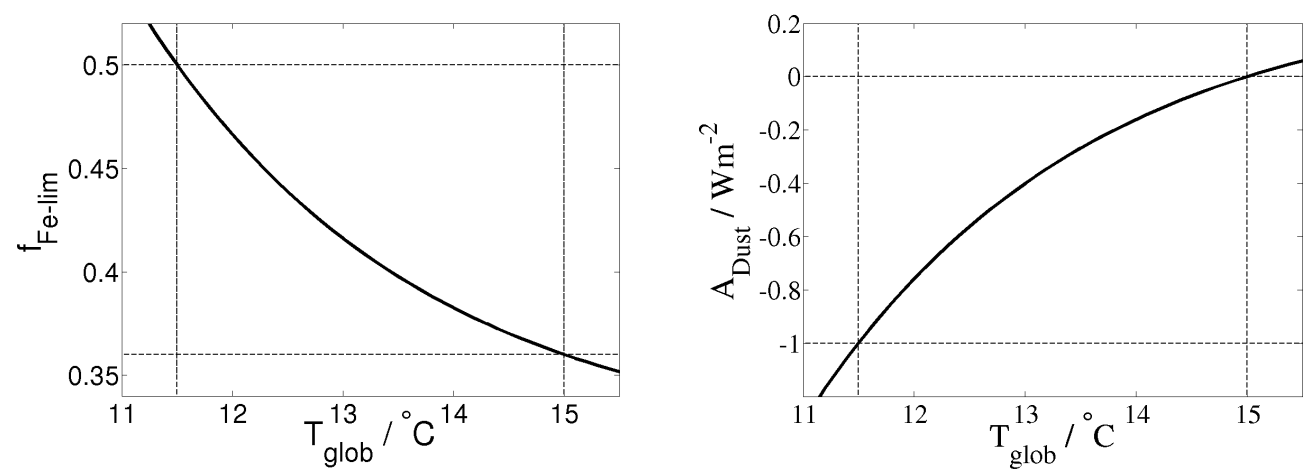

Figure 5. Transition functions for iron-limitation factor $f_{F e-l i m}$ (left panel) and for additional radiative forcing due to dust $A_{\text {Dust }}$ (right panel) variations between LGM and PI.

for the iron limitation factor and

$A_{\text {Dust }}=\frac{-e^{-0.4 \cdot T_{\text {glob }}}+e^{-6}}{e^{-4.6}-e^{-6}}$

for the additional dust radiative forcing can be established. In Fig. 5 these two functions are shown within the range of interest between 15 and $11.5^{\circ} \mathrm{C}$ in $\mathrm{T}_{g l o b}$ as applied in the simulations.

\section{Various ${ }^{14} \mathrm{C}$ production rates}

Here, we present the three cosmogenic ${ }^{14} \mathrm{C}$ production rate time series from the studies by Muscheler et al. (2004); Laj et al. (2004) and Hain et al. (2014) that were applied in our experiments. Based on 
the GLobal PaleoIntensity Stack (GLOPIS-75), Laj et al. (2004) determined the ${ }^{14} \mathrm{C}$ production rate as a function of past changes in geomagnetic field intensity using the conversion of Masarik and Beer (1999). Hain et al. (2014) have further processed these data with a Monte-Carlo simulation with 1000 members of randomised magnetic field strength records within the GLOPIS-75 uncertainty envelope and a more recent ${ }^{14} \mathrm{C}$ production rate model by Kovaltsov et al. (2012) with updated cosmic ray spectra. Muscheler et al. (2004) have used a different approach to infer the ${ }^{14} \mathrm{C}$ production rate across the last $25 \mathrm{ka}$ based on high resolution ${ }^{10} \mathrm{Be}$ measurements from GRIP and GISP2 ice cores. Assuming that the atmospheric processes of ${ }^{10} \mathrm{Be}$ (attachment on aerosols and deposition after a mean residence time of $1-2$ years in the atmosphere) are understood, the ${ }^{14} \mathrm{C}$ production rate can be estimated rather directly, because ${ }^{10} \mathrm{Be}$ and ${ }^{14} \mathrm{C}$ are produced by similar processes in the atmosphere (Lal and Peters, 1967, Masarik and Beer, 1999). This reconstruction takes into account all probable causes of production rate variations, such as variations in geomagnetic field, solar activity and/or in the interstellar galactic cosmic rays flux (Muscheler et al. 2004).

In their studies, Muscheler et al. (2004) as well as Laj et al. (2004) only provide normalised (around 1) values for the ${ }^{14} \mathrm{C}$ production rate, because the determination of the absolute values is very uncertain. Only the more recent study by Hain et al. (2014) provides these absolute values (in atoms $/ \mathrm{cm}^{-2} \mathrm{~s}$ ). For this reason, we scaled the two other data sets by factors that yield ${ }^{14} \mathrm{C}$ production rates throughout the last $25 \mathrm{kaBP}$ that are close to the data by Hain et al. (2014) and moreover, lead to atmospheric $\Delta^{14} \mathrm{C}$ results close to the data based reconstructions at the beginning of the MI in the DCESS simulations. An evaluation of good fits for these scaling factors yielded 1.5. $10^{4}$ atoms $\cdot \mathrm{cm}^{2} \mathrm{~s}^{-1}$ for the data by Muscheler et al. (2004) and $1.35 \cdot 10^{4} \mathrm{atoms} \cdot \mathrm{cm}^{2} \mathrm{~s}^{-1}$ for the data by Laj et al. (2004). For the box diffusion model-calculated ${ }^{14} \mathrm{C}$ production rate (Muscheler et al. 2005, see Fig. 6 in the manuscript), the most likely absolute values are generated by multiplication with $1.8 \cdot 10^{4}$ atoms $\cdot \mathrm{cm}^{2} \mathrm{~s}^{-1}$ (R. Muscheler, personal communication, 2015). In Fig. 6, the three ${ }^{14} \mathrm{C}$ production rate time series are shown.

250 Generally, the three individual ${ }^{14} \mathrm{C}$ production rates show similar patterns across the last $25 \mathrm{kaBP}$, although with a couple of differences. The data by Hain et al. (2014) and by Laj et al. (2004) are derived from the same approach and the general features and local extrema therefore show the same timing, although the time series by Hain et al. (2014) seems somewhat smoother with a smaller general trend. The data by Muscheler et al. (2004) shows far stronger and more high-frequent fluctuations than the other two data sets, the general trend, however, is similar. Only between 20 and $23 \mathrm{kaBP}$ do the time series of the different approaches show an opposing behaviour. While the data set by Muscheler et al. (2004) shows a minimum during that period, the other two time series possess maxima here. Between the beginning and the end of the MI, all data sets are similar. A reduction of $0.11 \mathrm{atmos} / \mathrm{cm}^{2} s$ can be seen in the data by Hain et al. (2014), $0.19 \mathrm{atmos} / \mathrm{cm}^{2} s$ in the data by Laj et al. (2004) and even a slight increase of $0.02 \mathrm{atmos} / \mathrm{cm}^{2} s$ in the data by Muscheler et al. (2004). 


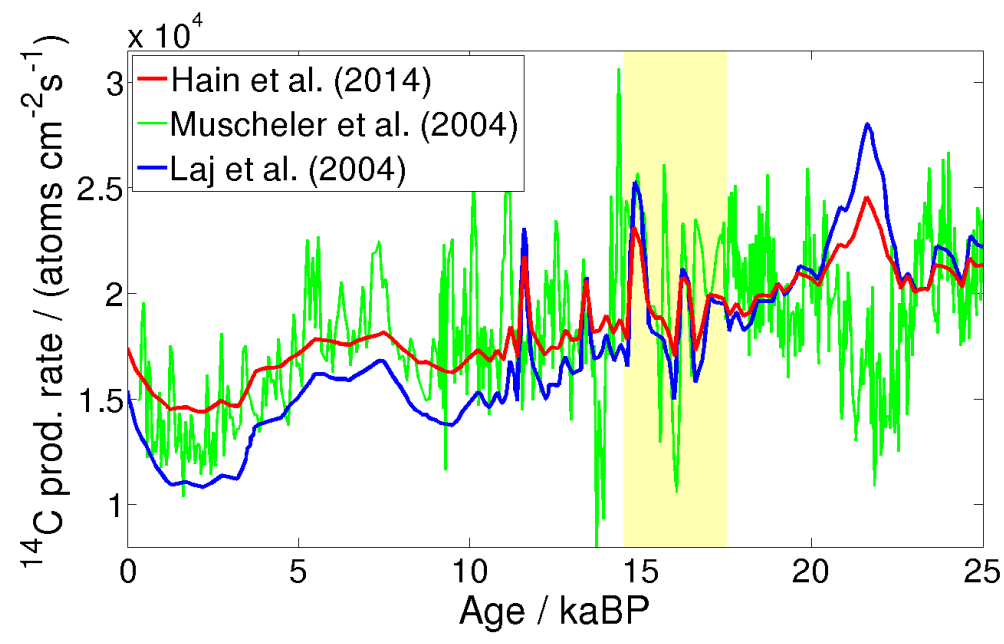

Figure 6. Three estimates of the ${ }^{14} \mathrm{C}$ production rate. Muscheler et al. (2004) (green) scaled by 1.5, Laj et al. (2004) (blue), scaled by 1.35 and Hain et al. (2014) (red). The MI is indicated by yellow shading.

\section{Isotope ratio definitions}

Isotope ratios are determined by

$\delta^{13} C=\left(\frac{\frac{{ }^{13} C}{12 C}}{R_{p d b}^{13}}-1\right) \cdot 1000$

with the 'Pee-Dee Belemnite' standard $R_{p d b}^{13}=0.0112372$ (Zhang et al., 1990) for the ${ }^{13} \mathrm{C} /{ }^{12} \mathrm{C}$ ratio 265

and by

$\Delta^{14} C=\left[\frac{\frac{{ }^{14} C}{12 C}}{R_{\text {oas }}^{14}}\left(\frac{R_{p d b}^{13} \cdot 0.975}{{ }^{13} C}\right)^{2}-1\right] \cdot 1000$

with the 'Oxalic Acid Standard' $R_{\text {oas }}^{14}=1.176 \cdot 10^{-12}$ for the ${ }^{14} \mathrm{C} /{ }^{12} \mathrm{C}$ ratio (Karlen et al. 1964 ). 


\section{References}

Adams, J. M., Faure, H., Faure-Denard, L., McGlade, J. M., and Woodward, F. I. (1990). Increase in terrestrial carbon storage from the Last Glacial Maximum to the present. Nature, 348:711-714.

Burke, A. and Robinson, L. F. (2012). The Southern Ocean's Role in Carbon Exchange During the Last Deglaciation. Science, 335:557-561.

Chapin, I. I. I., Stuart, F., Matson, P. A., and Vitousek, P. (2011). Principles of terrestrial ecosystem ecology.

Friedlingstein, P., Cox, P., Betts, R., Bopp, L., von Bloh, W., Brovkin, V., Cadule, P., Doney, S., Eby, M., Fung, I., Bala, G., John, J., Jones, C., Joos, F., Kato, T., Kawamiya, M., Knorr, W., Lindsay, K., Matthews, H. D., Raddatz, T., Rayner, P., Reick, C., Roeckner, E., Schnitzler, K.-G., Schnur, R., Strassmann, K., Weaver, A. J., Yoshikawa, C., and Zeng, N. (2006). Climate-carbon cycle feedback analysis: Results from the $C^{4}$ MIP model Intercomparison. Journal of Climate, 19:3337-3353.

Gerber, S., Joos, F., and Prentice, C. (2004). Sensitivity of a dynamic global vegetation model to climate and atmospheric $\mathrm{CO}_{2}$. Global Change Biology, 10:1223-1239.

Gower, S. T., Kucharik, C. J., and Norman, J. M. (1999). Direct and indirect estimation of leaf area index, $\mathrm{f}_{A} P A R$, and net primary production of terrestrial ecosystems. Remote sensing of environment, 70(1):29-51.

Hain, M. P., Sigman, D. M., and Haug, G. H. (2014). Distinct roles of the Southern Ocean and North Atlantic in the deglacial atmospheric radiocarbon decline. Earth and Planetary Science Letters, 394:198-208.

Jouzel, J., Masson-Delmotte, V., Cattani, O., Dreyfus, G., Falourd, S., Hoffmann, G., Minster, B., Nouet, J., Barnola, J. M., Chappellaz, J., Fischer, H., Gallet, J. C., Johnsen, S., Leuenberger, M., Loulergue, L., Luethi, D., Oerter, H., Parrenin, F., Raisbeck, G., Raynaud, D., Schilt, A., Schwander, J., Selmo, E., Souchez, R., Spahni, R., Stauffer, B., Steffensen, J. P., Stenni, B., Stocker, T. F., Tison, J. L., Werner, M., and Wolff, E. W. (2007). Orbital and Millennial Antarctic Climate Variability over the Past 800,000 Years. Science, 317(5839):793-796.

Karlen, I., Olsson, I. U., Kallburg, P., and Kilici, S. (1964). Absolute determination of the activity of two 14C dating standards. Arkiv Geofysik, 4:465-471.

Kovaltsov, G. A., Mishev, A., and Usoskin, I. G. (2012). A new model of cosmogenic production of radiocarbon

${ }^{14} \mathrm{C}$ in the atmosphere. Earth and Planetary Science Letters, 337:114-120.

Laj, C., Kissel, C., and Beer, J. (2004). High resolution global paleointensity stack since 75 kyr (GLOPIS-75) calibrated to absolute values. in: Geophysical Monograph Series (AGU), 145:255-265.

Lal, D. and Peters, B. (1967). Cosmic rays produced radioactivity on the Earth. Encyclopedia of Physics, Cosmic Rays II, 46:551-612.

Lambert, F., Bigler, M., Steffensen, J. P., Hutterli, M., and Fischer, H. (2012). Centennial mineral dust variability in high-resolution ice core data from Dome C, Antarctica . Climate of the Past, 8:609-623.

Lambert, F., Kug, J.-S., Park, R. J., Mahowald, N., Winckler, G., Abe-Ouchi, A., O’ishi, R., Takemura, T., and Lee, J.-H. (2013). The role of mineral-dust aerosols in polar temperature amplification. Nature Climate Change, 3:487-491.

Lambert, F., Tagliabue, A., Shaffer, G., Lamy, F., Winckler, G., Farias, L., Gallardo, L., and De Pol-Holz, R. (2015). Dust fluxes and iron fertilization in Holocene and Last Glacial Maximum climates. Geophysical Research Letters, 42(14):6014-6023. 
Maher, B. A., Prospero, J. M., Mackie, D., Gaiero, D., Hesse, P., and Balkanski, Y. (2010). Global connections between aeolian dust, climate and ocean biogeochemistry at the present day and at the last glacial maximum. Earth-Science Reviews, 99:61-97.

Mahowald, N., Yoshioka, M., Collins, W., Conley, A., Fillmore, D., and Coleman, D. (2006). Climate response and radiative forcing from mineral aerosols during the glacial maximum, pre-industrial, current and doubledcarbon dioxide climates. Geophysical Research Letters, 33:L20705.

Masarik, J. and Beer, J. (1999). Simulation of particle fluxes and cosmogenic nuclide production in the Earth's atmosphere. Journal of Geophysical Research, 104:12099-12111.

Matney, M. (2012). On the Probability of Random Debris Reentry Occuring on Land or Water. Orbital Debris Quaterly News, 16(1):5.

Muscheler, R., Beer, J., Kubik, P. W., and Synal, H.-A. (2005). Geomagnetic field intensity during the last 60,000 years based on ${ }^{10} \mathrm{Be}$ and ${ }^{36} \mathrm{Cl}$ from the Summit ice cores and ${ }^{14} \mathrm{C}$. Quaternary Science Reviews, 24:1849-1860.

Muscheler, R., Beer, J., Wagner, G., Laj, C., Kissel, C., Raisbeck, G. M., Yiou, F., and Kubik, P. W. (2004). Changes in the carbon cycle during the last deglaciation as indicated by the comparison of ${ }^{10} \mathrm{Be}$ and ${ }^{14} \mathrm{C}$ records. Earth and Planetary Science Letters, 219:325-340.

Peng, C. H., Guiot, J., and van Campo, E. (1998). Estimating changes in terrestrial vegetation and carbon storage: Using paleoecological data and models. Quaternary Science Reviews, 17:719-735.

Prentice, K. C. and Fung, I. Y. (1990). The sensitivity of terrestrial carbon storage to climate change. Nature, 346:48-51.

Prentice, K. C., Harrison, S. P., and Bartlein, P. J. (2011). Global vegetation and terrestrial carbon cycle changes after the last ice age. Nature, 189:988-998.

Saugier, B., Roy, J., and Mooney, H. A. (2001). 23 - Estimations of global terrestrial productivity: converging toward a single number. Terrestrial global productivity: past, present and future, pages 543-557.

Schuur, E. A. G., McGuire, A. D., Schädel, C., Grosse, G., Harden, J. W., Hayes, D. J., Hugelius, G., Koven, C. D., Kuhry, P., Lawrence, D. M., Lawrence, D. M., Natali, S. M., Olefeldt, D., Romanovsky, V. E., Schaefer, K., Turetsky, M. R., Treat, C. C., and Vonk, J. E. (2015). Climate change and the permafrost carbon feedback. Nature, 520(7546):171-179.

Shaffer, G., Malskær Olsen, S., and Pepke Pedersen, J. (2008). Presentation, calibration and validation of the low-order, DCESS Earth System Model (Version 1). Geoscientific Model Development, 1:17-51.

Shaffer, G., Olsen, S. M., and Pedersen, O. P. (2009). Long-term ocean oxygen depletion in response to carbon dioxide emissions from fossil fuels. Nature Geoscience, 2:105-109.

Sterner, R. W. and Elser, J. J. (2002). Ecological Stoichiometry: The Biology of Elements from Molecules to the Biosphere, volume 25(9). Princeton University Press.

Watson, A. J. and Naveira Garabato, A. C. (2006). The role of Southern Ocean mixing and upwelling in glacial-interglacial atmospheric $\mathrm{CO}_{2}$ change. Tellus, 58B:73-87.

Winckler, G., Anderson, R. F., Fleisher, M. Q., McGee, D., and Mahowald, N. (2008). Covariant GlacialInterglacial Dust Fluxes in the Equatorial Pacific and Antarctica. Science, 320(5872):93-96.

Zech, R. (2012). A permafrost glacial hypothesis - Permafrost carbon might help explaining the Pleistocene ice ages. Quaternary Science Journal, 61 (1):84-92. 
Zhang, Q. L., Chang, T. L., and Li, W. J. (1990). A Calibrated Measurement of the Atomic-weight of Carbon. Chinese Science Bulletin, 35(4):290-296.

Zheng, D., Prince, S., and Wright, R. (2003). Terrestrial net primary production estimates for 0.5 grid cells from field observations - a contribution to global biogeochemical modeling. Global Change Biology, 9(1):46-64.

Zickfeld, K., Eby, M., Weaver, A. J., Alexander, K., Crespin, E., Edwards, N. R., Eliseev, A. V., Feulner, G., Fichefet, T., Forest, C. E., Friedlingstein, P., Goosse, H., Holden, P. B., Joos, F., Kawamiya, M., Kicklighter, D., Kienert, H., Matsumoto, K., Mokhov, I. I., Monier, E., Olsen, S. M., Pedersen, J. O. P., Perrette, M., Philippon-Berthier, G., Ridgwell, A., Schlosser, A., Schneider Von Deimling, T., Shaffer, G., Sokolov, A., Spahni, R., Steinacher, M., Tachiiri, K., Tokos, K. S., Yoshimori, M., Zeng, N., and Zhao, F. (2013). Long-term climate change commitment and reversibility: An EMIC intercomparison. Journal of Climate, 26(16):5782-5809. 